\title{
Hemiageusia, Hemianaesthesia and Hemiatrophy of the Tongue
}

\author{
Michael J. Strong and John H. Noseworthy
}

\begin{abstract}
A patient with a submandibular gland carcinoma was found clinically to have a unilateral chorda tympani, lingual and hypoglossal nerve deficit. This unique neurological entity of loss of taste sensation of one-half of the tongue (hemiageusia), hemianaesthesia and hemiatrophy of the tongue, has not previously been reported.
\end{abstract}

RÉSUMÉ: L'hémiageusie, I'hémianesthesie, et l'hémiatrophie de la langue Description d'un patient porteur d'un carcinome de la glande sous-maxillaire qui présentait cliniquement un déficit unilatéral de la fonction des nerfs suivants: corde du tympan, lingual et hypoglosse. Cette entité neurologique unique consistant en une perte du sens du goût sur la moitié de la langue (hémiageusie), une hémianesthésie et une hémiatrophie de la langue, n’a encore jamais été rapportée.

Can. J. Neurol. Sci. 1986; 13:109-110

Lesions of the floor of the mouth occasionally present with predominantly neurological manifestations. While the entity of hemianaesthesia and hemiatrophy of the tongue with loss of taste sensation has not previously been described, an understanding of the regional anatomy of the submandibular fossa can lead to only one localization for the lesion in this triad. We have studied a patient presenting with these findings who was found to have a submandibular gland carcinoma.

\section{CASE REPORT}

A 72-year-old female presented with an 18 month history of progressive dysphagia, a four month awareness of the need to repeat herself to be clearly understood associated with a loss of taste sensation along the right half of her tongue and an inability to protrude her tongue. At the time of neurological assessment her main complaints included a decreased ability to articulate, dysphagia and complete loss of taste with occasional burning dyesthesia along the right side of the tongue.

Neurological examination was considered normal apart from the following findings limited to the right half of the tongue: complete hemianaesthesia, complete loss of taste of the anterior two-thirds, and marked hemiatrophy with inability to protrude the tongue. Sensation remained intact on the inferior alveolar ridge, buccal mucosa and chin. No associated facial, pterygoid or palate weakness was noted. Direct vocal cord visualization showed normal cord movement. Although initially missed, an area of mild induration of the submandibular fossa was noted. Subsequent to this finding, CT scanning through the right submandibular gland revealed a mass lesion (Figure 1) which on resection proved to be a $3.5 \times 1.7 \mathrm{~cm}$. moderately differentiated squamous cell carcinoma of the gland.

\section{Discussion}

The anatomical localization of a unilateral lesion of the trigeminal nerve distal to the origin of the inferior alveolar nerve in association with ipsilateral chorda tympani and hypoglossal nerve dysfunction is demonstrated by this instructive case. While intra-axial infiltration or degenerative processes should be considered, the clear lack of accompanying brainstem dysfunction and the striking peripheral nature of the trigeminal involvement renders this anatomically improbable. Similarly, consideration of the more commonly seen and well recognized cranial nerve syndromes reveals that sparing of cranial nerves $\mathrm{IX}, \mathrm{X}$ and $\mathrm{XI}$ would make either an intracranial, extra-axial or proximal extracranial lesion unlikely.'

An understanding of the regional anatomy of the involved nerves permits the localization of this triad of findings. The lingual nerve, a branch of the mandibular division of the trigeminal nerve, supplies common sensation from the anterior two-

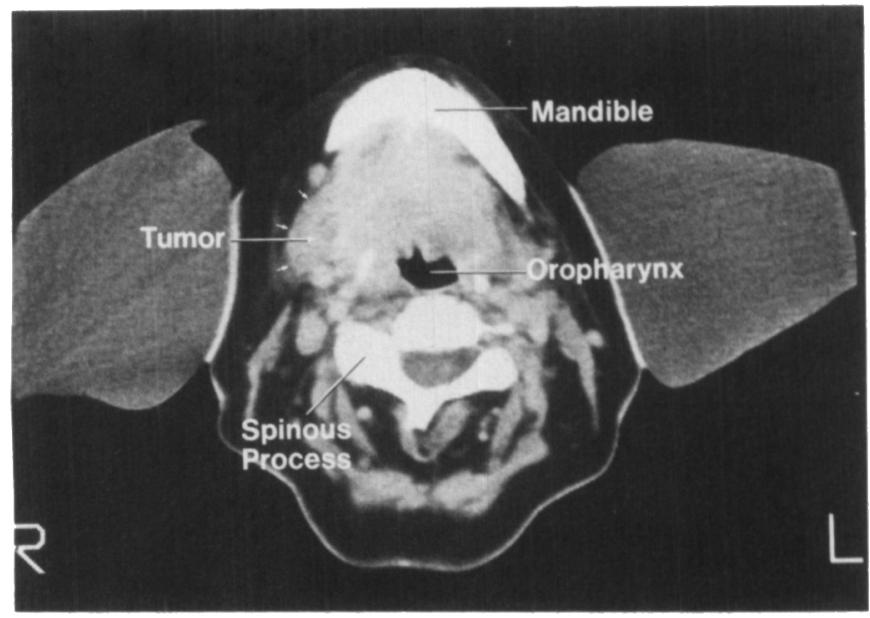

Figure I - Transverse CAT-scan through the levels of the submandibular gland demonstrating the tumor mass.

This paper was presented in part at the XXth Canadian Congress of Neurological Sciences, Montreal, Quebec, June 1985

From the Department of Clinical Neurological Sciences, University Hospital, London, Ontario

Received November 5, 1985. Accepted February 18, 1986

Reprint requests to: Dr. John H. Noseworthy, Department of Clinical Neurological Sciences, University Hospital, 339 Windermere Road, P.O. Box 5339, Postal Stn. A. London, Ontario, Canada N6A 5A5 
thirds of the tongue, the adjacent floor of the mouth and gums, and the sublingual gland. The chorda tympani joins the lingual nerve deep in the infratemporal fossa near the internal maxillary artery distal to the origins of the inferior alveolar and buccal nerves. As well as carrying preganglionic parasympathetic secretory fibres to the submandibular and sublingual glands, the chorda tympani carries special sensory fibres supplying taste to the anterior two thirds of the tongue. The inferior alveolar nerve runs in the ascending ramus of the mandible to supply sensation to the lower lip, chin and the inferior molar to incisor teeth. The buccal nerve, a branch of the anterior division of the mandibular nerve, crosses the anterior border of the

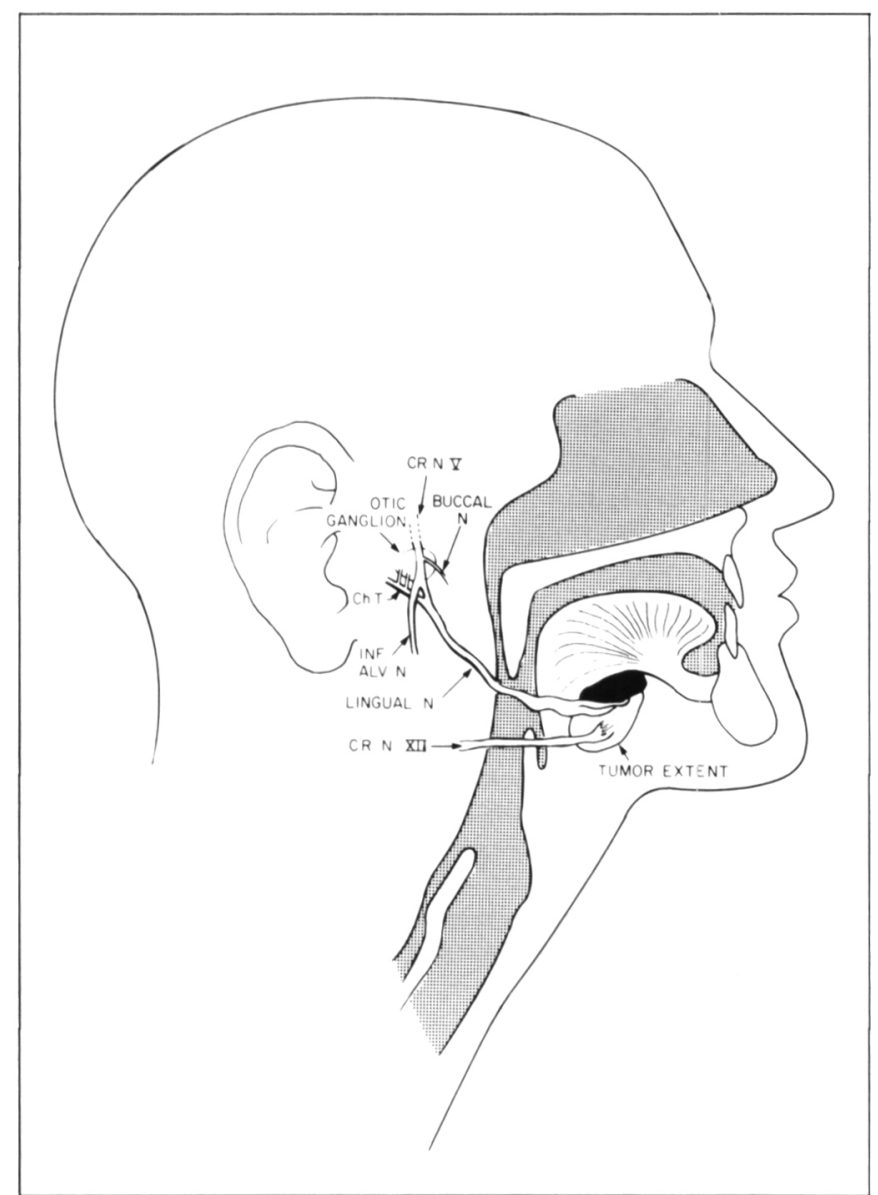

Figure 2 - Illustration of the Course of the Lingual Nerve. Note the insertion of the Chorda Tympani (Ch.T.) distal to the origin of the Inferior Alveolar Nerve (Inf.Alv.N.) and Buccal Nerve. mandibular ramus to supply sensory innervation to the buccal mucosa of the cheek to the angle of the mouth and to the buccal gingivae of the posterior mandibular teeth. ${ }^{2.3}$ A lesion which affects only taste and deep sensation of the tongue and spares the buccal mucosa, teeth and chin must therefore be in the distal lingual nerve. The hypoglossal nerve, however, after exiting from the hypoglossal canal and coursing downwards in the carotid sheath to the level of the occipital artery, passes deep to the tendon of the digastric muscle to pass between the mylohyoid and hyoglossus muscles to supply the intrinsic muscles of the tongue. ${ }^{4.5}$ It is only along the medial border of the deep portion of the submandibular gland, where the hypoglossal nerve courses inferiorly to the lingual nerve, ${ }^{6}$ that a single lesion could involve both nerves (Figure 2). The differential diagnosis of lesions in the submandibular fossa includes tumors of the submandibular gland (benign mixed tumors, malignant tumors or lymphoma) which rarely give rise to neurological symptoms, or chronic abscess (usually of dental origin). ${ }^{7}$

We have been unable to find any neurological or otolaryngological literature on this triad of findings and know of no eponymous term for this entity. We suggest that the syndrome of hemiageusia, hemianaesthesia and hemiatrophy of the tongue, as clearly illustrated by this case report, is the unique entity of a chorda tympani, lingual and hypoglossal nerve lesion in the submandibular triangle obviating the necessity for extensive neurological investigation.

\section{REFERENCES}

1. Adams RD, Victor M. Diseases of the cranial nerves (Chapter 46) In: Principles of Neurology, Third Edition. McGraw-Hill Inc., 1985: 1009.

2. Scott JH, Dixon AD. Anatomy of the Oral Region (Chapter 6). In: Anatomy for Students of Dentistry. Fourth Edition. New York: Churchill Livingstone, 1978: 304.

3. Kaufman L, Sowray JH, Rood JP. Mandibular Injections (Chapter 7). In: General Anaesthesia, Local Anaesthesia and Sedation in Dentistry. London: Blackwell Scientific Publications, 1982; 64.

4. Gates GA, Johns ME. Embryology and anatomy of the salivary glands (Chapter 4). In: Paparello MM, and Shumrick D. eds. Otolaryngology, Philadelphia: Saunders, 1980; 124.

5. Work WP, Bailey DG. Surgery of the major salivary glands. (Chapter 22). In: Paparella MM, and Shumrick D, eds. Otolaryngology, Philadelphia: Saunders, 1980; 2254.

6. Yeh S. The Salivary Glands (Chapter 19). In: Diseases of the Nose, Throat, Ear, Head and Neck. Thirteenth Edition. Philadelphia: Lea and Febiger. 1985; 304.

7. Batsakis JG. Neoplasms of the minor and "lessor" major salivary glands. In: Tumors of the Head and Neck. Second Edition, Baltimore: Williams and Wilkins, 1979: 94. 